\title{
Pneumocystis pneumonia in Cushing's syndrome due to ectopic ACTH.
}

\author{
Dimitris Papamargaritis ${ }^{1}$, Syed Jafery ${ }^{1}$, Ragini Bhake ${ }^{1}$, Narendra Reddy $^{1}$, Miles Levy $^{1}$ \\ ${ }^{1}$ Department of Endocrinology, University Hospitals of Leicester NHS trust, Leicester, UK
}

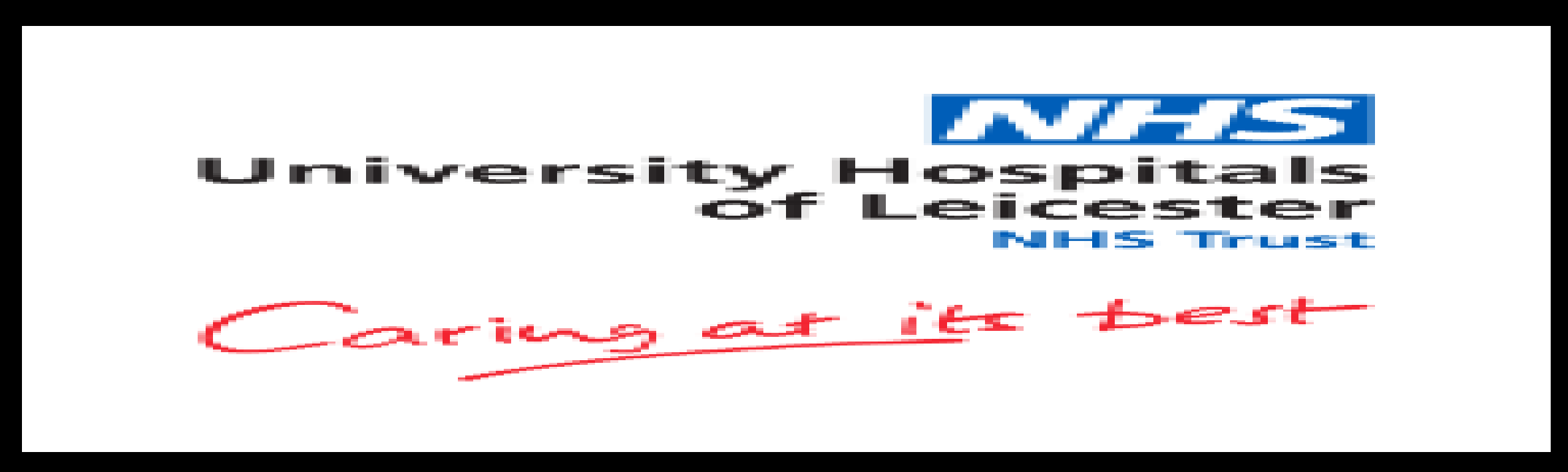

\section{Introduction}

- Opportunistic infections are a recognised complication of severe hypercortisolism.

- We report a case of Pneumocystis Jiroveci Pneumonia (PCP for formerly named Pneumocystis carinii pneumonia) in patient with ectopic Cushing's syndrome caused by a metastatic large cell neuroendocrine carcinoma of the lung.

\section{Case report}

- A 61-year old male attended the Acute Medical Unit for investigation and treatment of severe and recurrent hypokalaemia (K<2.5 mmol/l). Other cushingoid features included hypertension, easy bruising and central fat distribution.

- His random cortisol at presentation was $1404 \mathrm{nmol} / \mathrm{L}, 24-\mathrm{h}$ urine free cortisol of $6363 \mathrm{nmol} / 24 \mathrm{~h}$ (upper limit of normal 270) and plasma ACTH was $250 \mathrm{ng} / \mathrm{L}$ (normal $<50$ ) confirming a diagnosis of ACTH dependent Cushing's syndrome. A repeat 9 am cortisol was $>2000 \mathrm{nmol} / \mathrm{l}$

- Corticotrophin-Releasing Hormone (CRH) test (Table 1) was suggestive of ectopic ACTH secretion (ACTH increment <50\%).

- CT whole body demonstrated a left upper lobe lung nodule with multiple liver metastases.

- Liver biopsy and immune-histochemistry confirmed the diagnosis of a large cell neuroendocrine carcinoma, metastatic from the lung.

\section{Management and complications}

- Patient treated initially with Spironolactone $50 \mathrm{mg}$ od. Metyrapone $250 \mathrm{mg}$ tds started after confirmation of diagnosis of ectopic ACTH Cushing's disease for management of severe hypokalaemia and hypercortisolaemia. Metyrapone dose gradually increased to $750 \mathrm{mg}$ tds and ketoconazole was added to the treatment. There was improvement in serum cortisol $(655 \mathrm{nmol} / \mathrm{l})$ and potassium $(3.5 \mathrm{mmol} / \mathrm{l})$ levels.

- Decision from oncology MDT was for palliative chemotherapy.

- One week after initiation of treatment with metyrapone, patient developed cough, fever, shortness of breath and he was desaturating on air (Sa02:88\% on Air).

- He was treated with intravenous antibiotics for hospital acquired pneumonia and oxygen. A CXR (Figure 1) and a CTPA (Figure 2) showed bilateral upper lobe dense consolidation. Patient started on empirical treatment for PCP with co- trimoxazole (oral) and a broncho-alveolar lavage (BAL) confirmed the diagnosis.

- Treatment for PCP continued for 21 days, patient's condition improved and discharged from the hospital with oxygen. Decision from oncology team after discussion with patient was not to provide chemotherapy due to overall deterioration. Patient referred to McMillan palliative team for symptom control .

Table 1. CRH test results

\begin{tabular}{|c|c|c|}
\hline $\begin{array}{c}\text { Time } \\
\text { (min) }\end{array}$ & $\begin{array}{c}\text { Cortisol } \\
\text { (nmol/l) }\end{array}$ & $\begin{array}{c}\text { ACTH } \\
\text { (ng/L) }\end{array}$ \\
\hline-15 & $>2000$ & 197 \\
\hline 0 & $>2000$ & 166 \\
\hline 15 & $>2000$ & 194 \\
\hline 30 & $>2000$ & 189 \\
\hline 45 & $>2000$ & 221 \\
\hline 60 & $>2000$ & 228 \\
\hline 90 & $>2000$ & 194 \\
\hline 120 & $>2000$ & 216 \\
\hline
\end{tabular}

\begin{tabular}{|l|l|l|}
\hline & Value & $\begin{array}{l}\text { Normal } \\
\text { Range }\end{array}$ \\
\hline $\begin{array}{l}\text { Pancreatide } \\
\text { Polypeptide }\end{array}$ & $>500 \mathrm{pmol} / \mathrm{l}$ & $(0-300)$ \\
\hline VIP & $3 \mathrm{pmol} / \mathrm{l}$ & $(0-30)$ \\
\hline Glucagon & $80 \mathrm{pmol} / \mathrm{l}$ & $(0-50)$ \\
\hline Gastrin & $45 \mathrm{pmol} / \mathrm{l}$ & $(0-40)$ \\
\hline Somatostatin & $821 \mathrm{pmol} / \mathrm{l}$ & $(0-150)$ \\
\hline Chromagraphin A & $91 \mathrm{pmol} / \mathrm{l}$ & $(0-60)$ \\
\hline Chromagrophin B & $2391 \mathrm{pmol} / \mathrm{l}$ & $(0-150)$ \\
\hline
\end{tabular}

Figure 1. CXR

Figure 2. CTPA

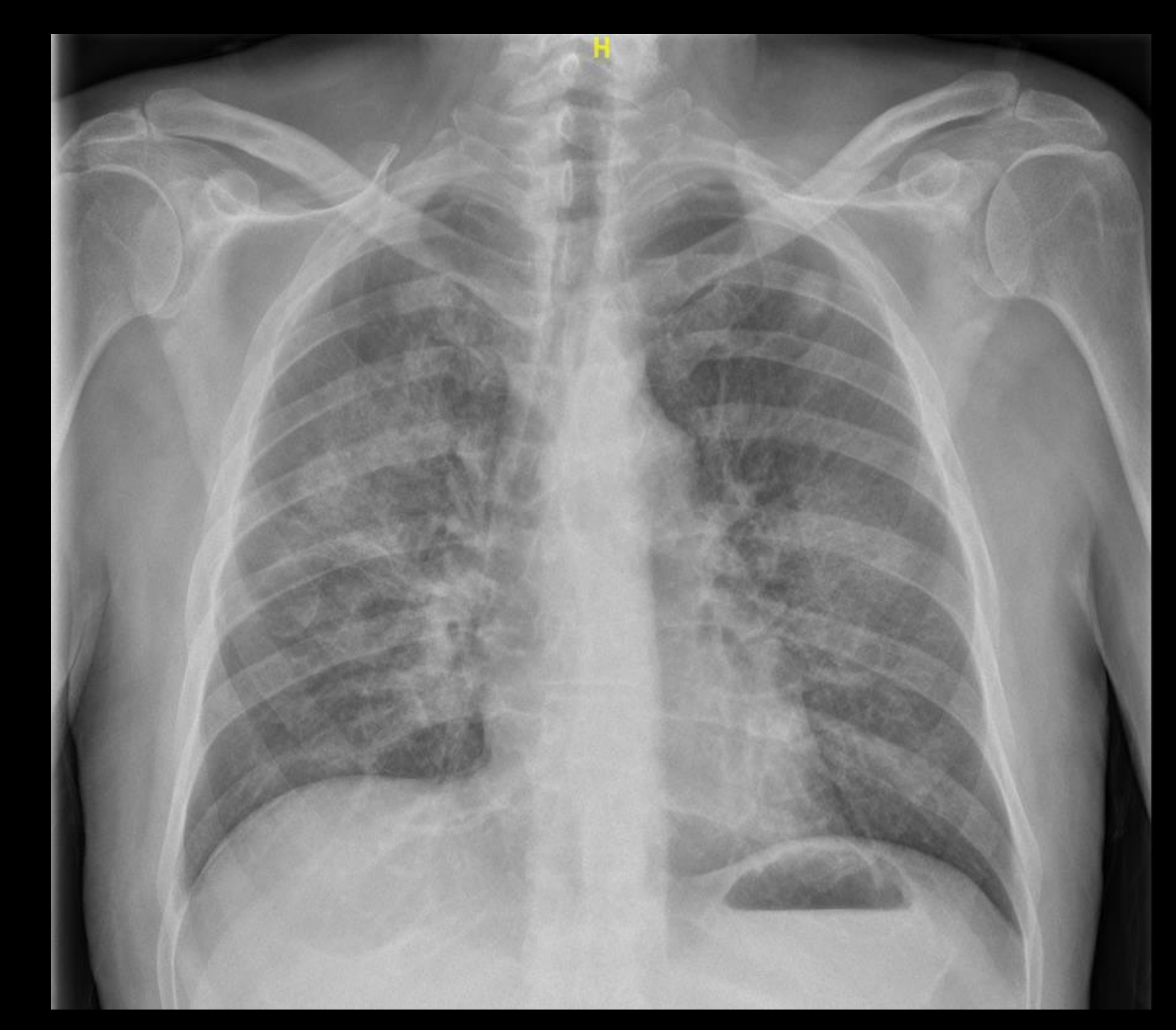

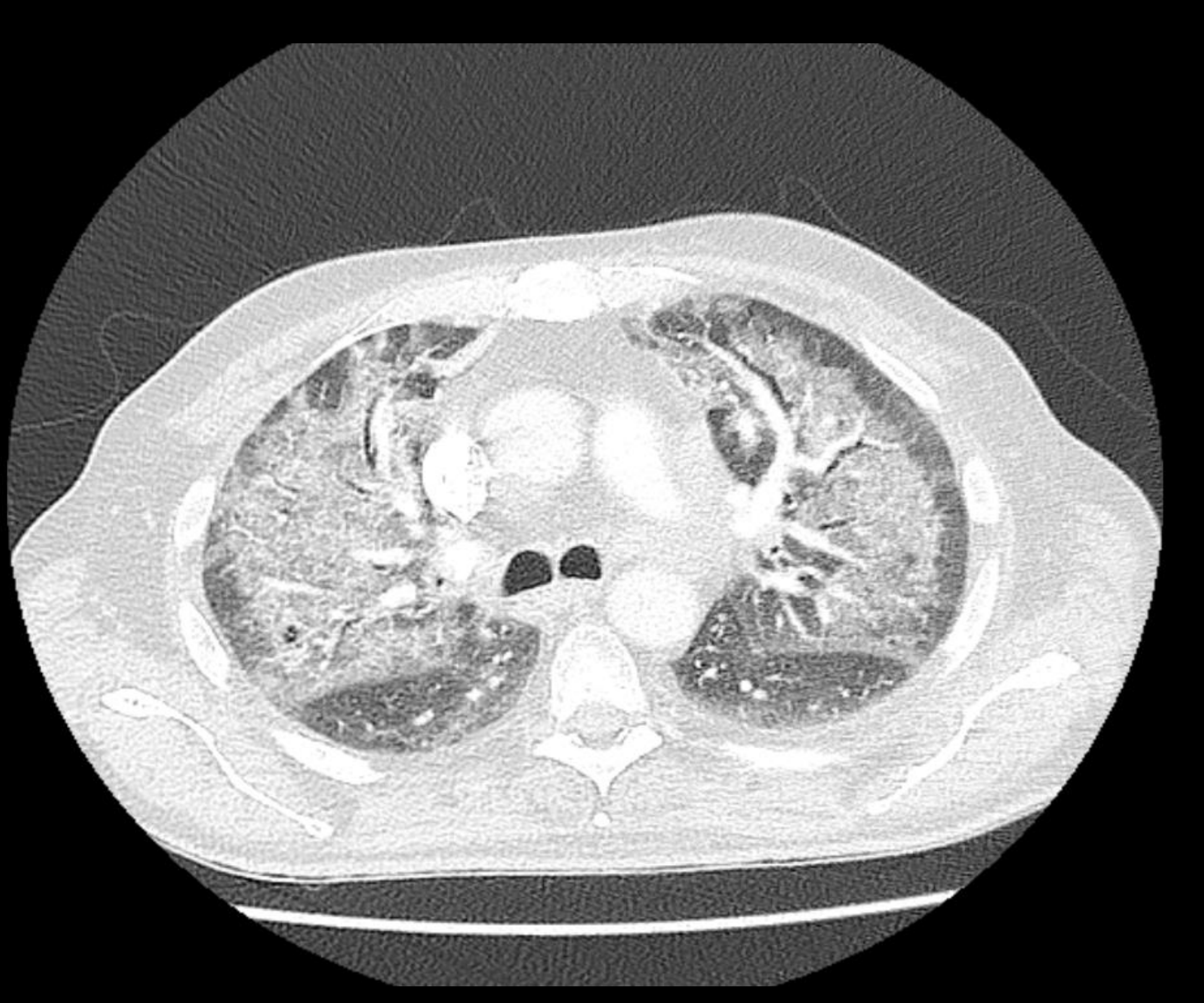

Discussion

- Similar to our case, PCP has been diagnosed after initiation of cortisol-lowering therapy in the majority of the reported cases in patients with Cushing's syndrome ${ }^{1}$.

- This suggests that immune reconstitution is an important component or even a prerequisite for development of clinically overt PCP in this population. There seems to be a relationship between the degree of hypercortisolism and the susceptibility to opportunistic infections².

- Our case highlights the fact that patients with severe hypercortisolaemia, more commonly seen in ectopic ACTH syndrome, may be at particular risk of PCP infection following treatment with cortisol-lowering agents.

- Prophylaxis against PCP should be considered before starting cortisol-lowering therapy in order to minimise the risk of PCP1,3.

\section{References}

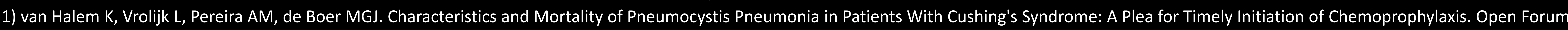
Infect Dis. 2017 Jan 30;4(1).

2. Sarlis NJ, Chanock SJ, Nieman LK. Cortisolemic indices predict severe infections in Cushing syndrome due to ectopic production of adrenocorticotropin. J Clin Endocrinol Metab 2000; 85: 42-47.

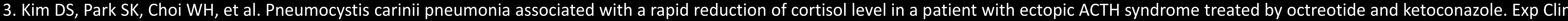

Endocrinol Diabetes 2000; 108: 146-50. 